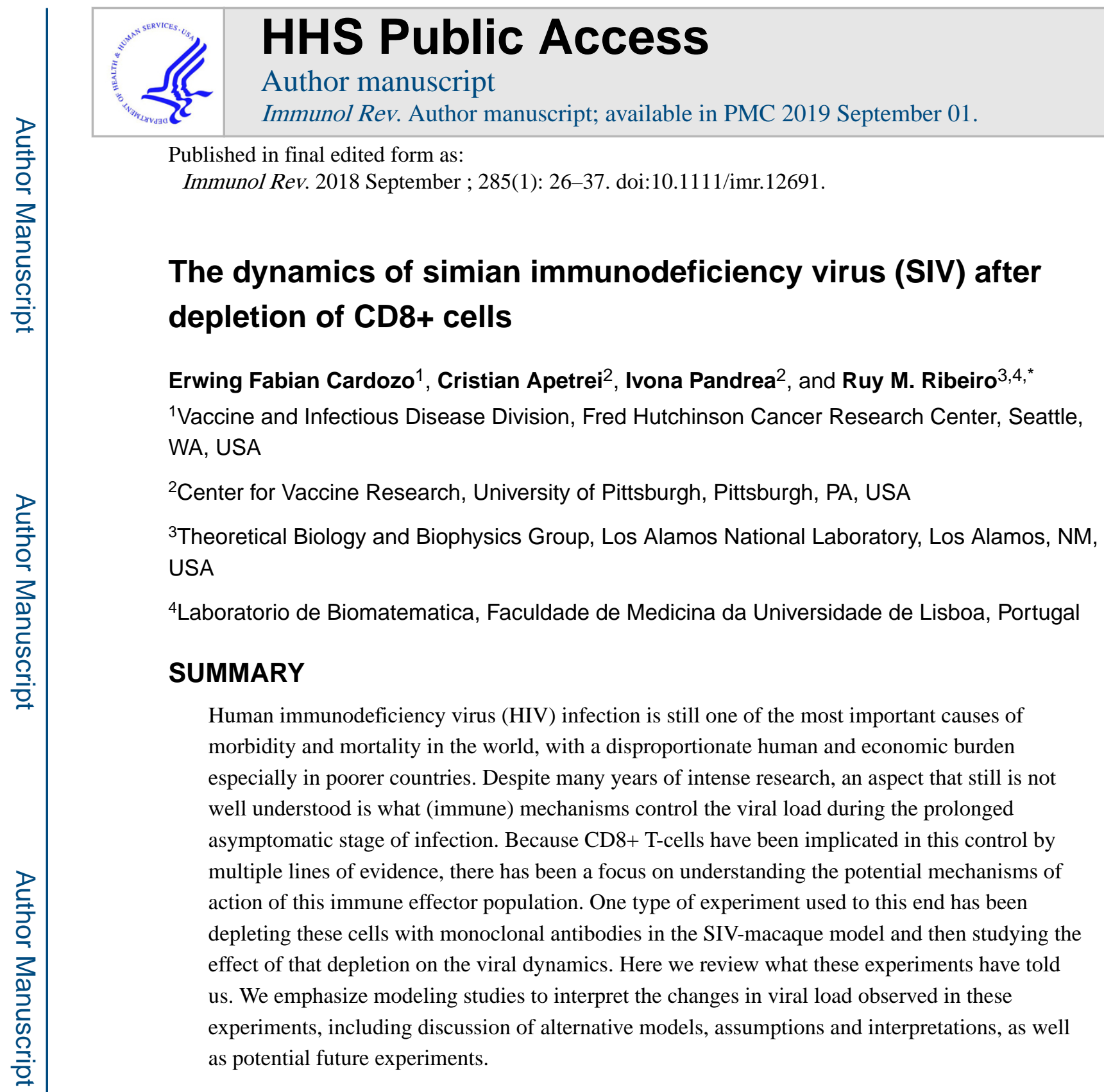

\title{
Keywords
}

dynamical modeling; mathematical modeling; ART; viral dynamics

\section{HIV INFECTION}

\begin{abstract}
Human immunodeficiency virus (HIV) is still one of the biggest worldwide causes of morbidity and mortality due to an infectious disease. HIV infects cells of the immune system, particularly CD4+ T cells and macrophages. If untreated, HIV eventually leads to immunodeficiency. As the number of CD4+ T cells decreases during the asymptomatic
\end{abstract}

\footnotetext{
*Address correspondence and reprint requests to: Prof. Ruy M Ribeiro, Laboratorio de Biomatematica, Faculdade de Medicina da Universidade de Lisboa, Av. Egas Moniz, 1649 Lisboa. ruyribeiro@ medicina.ulisboa.pt. Tel: +351 217999580.

8. CONFLICT OF INTERESTS

The authors declare that they do not have any conflict of interests regarding the material presented in this review.
} 
phase of infection, the HIV-infected individual has more difficulty fighting a suite of opportunistic diseases, which in the end are the cause of death.

During the initial stage of infection (called acute, primary infection), the viral levels increase exponentially over the first few weeks, reach a peak after 2-4 weeks from the time of infection and then decay until the viral load more or less stabilizes at the chronic phase setpoint level, starting from approximately 4-6 weeks post-infection (1). The chronic phase of viral infection is a protracted period with variable duration, during which the patient is asymptomatic and the viral load is relatively stable (2). However, the number of CD4+ T cells declines continuously over this period and when the number of these cells falls below 200 cells/ $\mu$, the patient enters the stage of AIDS (acquired immunodeficiency syndrome). This stage is traditionally characterized by the opportunistic diseases that eventually lead to the patient death. With the advent of antiretroviral therapy (ART), this classic pattern of disease progression, opportunistic infection and cancers was replaced with a more proteiform clinical presentation, characterized by multiple comorbidities triggered by persistent inflammation, such as hypercoagulability, cardiovascular disease, osteoporosis, non-alcoholic fatty liver disease, renal disease or accelerated aging (3-5).

One of the most puzzling aspects of HIV infection is that it is one of the few (perhaps the only) infections for which there is no reliable record of an infected person recovering without medical help. And indeed, with the exception of a very special case (6), no one has ever been able to eradicate the virus once infected, even in the setting of very powerful antiretroviral therapy. This observation is even more difficult to understand because HIV elicits vigorous immune responses, including innate, humoral and cellular effector mechanisms (7). For example, it has been clearly described that cellular immune responses, as measured by antigen-specific CD8+ T cell expansion, are similar or greater in HIV compared to other chronic diseases $(8,9)$.

Fortunately, ART is very efficient in reducing viral loads to undetectable levels (e.g., $<50$ copies $/ \mathrm{ml}$ ) in the vast majority of treated infected individuals. However, ART is not available to everyone infected. Furthermore, ART is virostatic, i.e., it reduces viral load, but does not lead to viral eradication. Thus, an important goal of HIV research is the development of a safe and effective vaccine to prevent infection in the first place. To this end, it is crucial to have a better understanding of immunity against the virus.

\section{HIV IMMUNE CONTROL}

Although it is still not clear what controls HIV viral load levels during the prolonged asymptomatic stage, when viral loads are relatively stable over months to years (2), several immune effector mechanisms are implicated, including innate responses (especially early on), antibody responses and cellular immune responses $(7,10)$. Among these, the most studied, and (perhaps consequently) the one for which there is the most evidence for an effect in controlling HIV, is the cellular immune response mediated by CD8+ T cells (11).

Several lines of evidence indicate that CD8+ T cells are an important factor in controlling HIV infection. This evidence includes the temporal association between HIV-1 decline after 
peak viremia in acute infection and the appearance of a CD8+ T-cell specific response (12), the association between an infected person's human leukocyte antigen (HLA) genotype and the course of infection (pathogenesis) and viral load set-point $(13,14)$; the mutation of virus at key residues (epitopes) to escape the immune response pressure of CD8+ T cells $(15,16)$, leading to an effective adaptation of the virus to persist in the infected host. This is confirmed at the population level as an evolution of the virus to adapt to prevalent HLA genotypes (17). Meanwhile, experiments designed to change the numbers of CD8+ T cells in circulation have an important (but variable) impact on viral load. These include experiments to increase the number of CD8+ T cells, such as infusion of these cells (18-24) and studies of vaccines leading to large expansions of the circulating CD8+ T-cell counts $(25,26)$. The opposite approach, trying to reduce CD8+ cells, by infusion of depleting antibodies, has also been attempted in simian immunodeficiency virus (SIV) animal models, usually leading to significant increases in viral load $(27,28)$.

Alternative interpretations of these various results point to a more limited impact of CD8+ Tcell responses in viral control. Thus, for example, the viral decay from the peak is indeed concomitant with the appearance of HIV-specific CD8+ T cells, but could also be explained by the reduction in target cell availability as a result of virus cytopathic effects (29). Furthermore, while it is expected that the control of viral load during treatment should depend on the quality of the CD8+ T-cell response, a study specifically analyzing the effect of HLA on the viral dynamics observed in patients put on antiretroviral treatment found no difference between protective alleles and other HLA types (30). The same is true of treatments early and late in infection, when it would be expected that the CD8+ T-cell response should be weaker, but no differences in viral dynamics were found $(29,31)$.

Thus, although multiple studies suggest a role for CD8+ T cells, the specific mechanisms by which these cells act in vivo are not understood. Nevertheless, the field is convergent in supporting the paradigm that HIV-specific cytotoxic CD8+ T cells kill HIV-1 infected cells $(27,28,32,33)$.

\section{CD8+ CELL DEPLETION EXPERIMENTS}

In mouse immunology, one of the preferred methods to understand the role of a gene/protein is to knock it out, and then compare the resulting phenotype with a wildtype animal (but see (34) for cautionary remarks). Since in humans and non-human primates (NHP) this is not feasible, one alternative is to use a blunter tool, such as depleting antibodies to remove a specific type of cell. To this end, anti-CD8 antibodies were developed to use in NHP (35, 36 ), which bind to CD8 $a$ and deplete cells expressing the CD8 a protein, including CD8+ T cells, but also CD8+ NK cells. Recently an antibody binding CD8 $\beta$ was also developed (36), which should be more specific for CD8+ T cells, including cytotoxic T lymphocytes (CTL). A typical SIV/NHP CD8+ cell depletion experiment is schematically represented in Fig. 1.

In the context of SIV/SHIV infection in the macaque, the best animal model for HIV, CD8+ cell depletion experiments have been performed to analyze multiple aspects of infection. The central question has been the effect of CD8+ T cells in controlling primary infection (28, $37-39)$ and chronic infection $(27,40)$. In the former, viral load dynamics are altered 
substantially and virus grows to a peak, but then remains at an elevated state until the reappearance of $\mathrm{CD} 8+$ cells, when the effect of the depleting antibody vanishes (28). Depletion in chronic infection leads to a variable increase in viral load from its quasi-steady state, which again resolves when the antibody is cleared and the CD8+ cells are restored (27) (Fig. 1B). These studies were taken as strong, if not the main, evidence for an important effect of CD8+ cells in controlling the virus - and likely were one of the key aspects for the rational to develop CD8+ T cell-based vaccines (26). Subsequent studies used this experimental approach to try to characterize in more detail the biology of HIV/SIV infection and the mechanisms of action of the CD8+ cells (41-47). For example, the contrasting results of depleting these cells in pathogenic models of SIV versus natural hosts of SIV, which do not develop overt disease, were analyzed in multiple studies (48-51).

One of the most common uses of $\mathrm{CD} 8+$ cell depletion is to investigate the effects of vaccine protocols. In these studies, a SIV vaccination and challenge protocol is implemented and when control of virus below the levels of placebo is found, often CD8+ cell depletion is performed to ascertain if these cells are important in the observed control (52-59). Another common use is in a model of SIV-induced encephalitis (SIVE). Depletion of CD8+ cells in primary infection leads to high viral loads and rapid progression, including a high incidence of SIVE, more than double in comparison to infection in non-depleted animals (60-62).

Here we focus on studies of CD8+ cell depletion during chronic infection, because some of these experiments have been analyzed in more detail through modeling. As schematically shown in Figure 1B, administration of a CD8-depleting antibody during chronic infection leads to a profound depletion of CD8+ cells in the periphery, although depletion at other sites, such as lymph node and mucosa, is usually less pronounced and more variable (63). At the same time, the viral load increases quickly.

\subsection{CD8-DEPLETION EXPERIMENTS DURING CHRONIC SIV INFECTION}

For a better understanding of the viral dynamics after CD8+ cell depletion, we reviewed in detail the data from 14 studies of experiments in macaques chronically infected with SIV and depleted of CD8+ cells. We included all studies that we could find with CD8+ cell depletion in SIV chronic infection, which had data on the viral dynamics in individual animals. Altogether, we collected data from 78 individual macaques. In Table 1, we summarize the main characteristics of these studies. (Note that Gadhamsetty et al. (64) also presented a summary of some of these studies.)

The studies included in this analysis had multiple objectives. Schmitz et al. and Jin et al. (27, 28) were two of the first studies to be published using CD8+ cell depletion with the aim of studying the role of CD8+ T cells in viral replication. They described the dynamics of viral load after this depletion in normal chronic infection. Two other studies analyzed the effect of depleting CD8+ cells during therapy with ART in chronic infection, to understand if death of productively infected cells was different in depleted and non-depleted animals (Klatt et al. and Wong et al. $(32,33)$ ). We will discuss these studies in more detail below. One study of ART analyzed the effect of transient early treatment, which results in lower viral loads, followed by depletion of CD8+ cells later in infection (Lifson et al. (65)). Three studies used depletion to try to understand the immune mechanisms responsible for viral control in elite 
controllers (Friedrich et al., Fukazawa et al. and Pandrea et al. (66-68)). In these elite controller macaques, viral load is maintained at very low levels for long periods of time without any type of treatment, but there is a large increase in viral load upon CD8+ cell depletion. To better understand the difference between good and poor controllers of viral load, one study performed a direct comparison of viral dynamics after CD8+ cell depletion in two groups of macaques with those characteristics (Chowdhury et al. (41)). In these last four studies, viral load control or not was an outcome of natural infection. Four other studies tested different vaccine protocols in which viral control is elicited by the vaccine, and then analyzed the importance of CD8+ cells in the immune mechanism responsible for viral control by depleting them (Metzner et al., Hansen et al., Amara et al., and Martins et al. (52, $56,57,69)$ ). Finally, one study analyzed viral control during early treatment with broadly neutralizing antibodies (Nishimura et al. (70)). Studies unrelated to vaccination or passive infusion of neutralizing antibodies challenged the animals using SIV strains SIVmac239 or SIVmac251. But studies that analyzed specific immune interventions used challenges with multiple different SHIV or SIV strains.

\subsection{DYNAMICS OF VIRAL LOAD POST CD8+ CELL DEPLETION}

In the studies analyzed, $\mathrm{CD} 8+$ cell depletion resulted in viral load increases that reached a peak on average 8.2 days later (range 2 to $\sim 22$ days) and this peak was on average $\sim 225$-fold above the pre-depletion viral load level, with viral load increases from $0.0 \log _{10}$ to 5.76 $\log _{10}$. An important caveat is that different sampling times in the multiple studies can influence these estimates. The peak viral load post-depletion is positively correlated with the viral load pre-depletion ( $\mathrm{r}=0.498, \mathrm{p}=4 \times 10^{-6}$ ) (Fig. 2A). But more interestingly, the foldincrease in viral load is also correlated with the pre-depletion viral load, but with a negative association $\left(\mathrm{r}=-0.778, \mathrm{p}=1 \times 10^{-16}\right)$ (Fig. 2B). Note that if depletion of CD8+ cells resulted in approximately the same fold-increase in different macaques, the former correlation would still be observed but not latter. This means that macaques with lower viral load do experience a much larger increase in virus during depletion. The viral load post-depletion increases with an average slope of 2.1/day. This slope of increase has a weak negative correlation with the pre-depletion viral load $\left(\mathrm{r}=-0.383, \mathrm{p}=7 \times 10^{-4}\right)$ (Fig. 3A), but a relatively strong positive correlation with the fold-increase post depletion $\left(\mathrm{r}=0.596, \mathrm{p}=1.7 \times 10^{-8}\right)$. That is, those macaques with the highest change in viral load, also increase the fastest (Fig. 3B).

One interpretation of these observations is that a better control imposed by CD8+ cells, in those macaques with lower viral loads pre-depletion, is revealed by the largest increases post-depletion. However, another possibility is that lower viral loads in those macaques also results in better preservation of CD4+ T cells, and thus more targets for infection when immune control is relaxed.

\section{MATHEMATICAL MODELING OF CD8+ CELL DEPLETION EXPERIMENTS}

The dynamic changes in viral load observed when CD8+ cells are depleted are indicative of the role of these cells in controlling the virus. However, they do not establish directly what the effector mechanism at play is. One way to try to address that issue is to analyze the data 
using mathematical models including multiple mechanisms of action for the CD8+ cells. Jin et al. (27) were the first to propose analyzing such data sets with a mathematical model.

They used a model proposed earlier by Mittler et al. (71) to study HIV infection dynamics. This model is defined by the following set of equations

$$
\begin{aligned}
& \frac{d T}{d t}=\lambda-d_{T} T-\beta V T \\
& \frac{d I}{d t}=\int f(\tau) \beta T(t-\tau) V(t-\tau) e^{-d_{T} \tau} d \tau-\delta I(t) \\
& \frac{d V}{d t}=p I-c V
\end{aligned}
$$

Here, $T$ represent target cells, of which CD4+ T cells are the most important, $I$ are productively infected cells and $V$ represents free virus. Target cells are generated at rate $\lambda$, die at per capita rate $d_{T}$ and can be infected at rate $\beta$ proportional to the concentration of free virus. Once a virus enters a target cell, there is a delay until that cell becomes productively infected and starts producing virus. This delay has a distribution $f(\mathrm{t})$ across all infected cells, and its implementation in the model gives rise to the integral in the equation for $I$. Only those cells that were infected some time before and survive the delay (indicated by the $e^{-d} T^{\tau}$ in the integral) become productively infected. These cells are lost, by multiple mechanisms, at rate $\delta$. Finally, virus is produced at rate $p=N \delta$ per infected cell, where $N$ is the burst size, and is cleared from circulation at rate $c$ per virion.

Using this model, Jin et al. (27) considered several putative effects for CD8+ cells. They reasoned that these cells could kill infected cells, such that in the absence of CD8+ cells, $\delta$ would be reduced (maximally to $0 /$ day). Or CD8+ cells could produce chemokines that reduce infection and thus by depletion of those cells, $\beta$ would increase. Finally, they also considered that $\mathrm{CD} 8+$ cells produce antiviral factors that block viral production, and absence of these cells would lead to higher levels of viral production, $p$. Interestingly, although all these putative mechanisms resulted in viral increase, none of them by itself provided dynamic profiles similar to those observed. Still, the most similar profile was obtained by an increase in $p$. This result was somewhat surprising, because it was expected that CD8+ T cells had a strong cytotoxic activity, and in that case killing of infected cells should be a major mechanism of viral control.

To directly analyze the potential effect of CD8+ cells in killing SIV-infected cells, two groups simultaneously and independently performed very similar antiretroviral treatment experiments in the context of CD8+ cell depletion $(32,33)$. In Figure 4A, we represent schematically the design of these studies. The hypothesis of these studies as stated in Klatt et al. (32) was "that CD8+ T cell-mediated CTL [cytotoxic T-lymphocyte] activity will result in reduced production of virions per infected cell due to a significant shortening of the average in vivo lifespan of productively SIV-infected cells". Both studies used a model similar to the one presented in equation (1), without considering the time delay and assuming that target cells remained approximately constant, $T_{0}$. In this case, the viral load during early therapy should change according to 


$$
V(t)=V_{0}\left(A e^{-\delta t}+(1-A) e^{-c t}\right)
$$

where $A=\frac{N \beta T_{0}}{c-\delta}$. The expectation, then, is that if CD8+ cells affect the death rate of infected cells, the administration of the CD8-depleting antibody would reduce $\delta$, resulting in a slower decline of viral load under therapy, as shown in Figure 4B.

The two studies found reassuring consistent results, but surprisingly there was no difference in the loss rate of infected cells, $\delta$, without or with CD8+ cell depletion (Fig. 4C). Klatt et al. concluded that "our experiments do challenge the common assumption that the main antiviral effect of CD8+ T cells is related to the direct killing of productively infected CD4+ T cells (i.e., CTL activity)" (32), and indeed Wong et al. also reached the same conclusion (33).

The authors of those studies confirmed an important effect of CD8+ cells, but refuted an effect on the life-span of productively infected cells. This led to a flurry of alternative hypothesis for the mechanism of action of CD8+ T cells, already in those two studies, but also in many subsequent papers. Two of the most interesting hypotheses were that either the effect of CD8+ cells was i) through non-cytolytic effects that did not reduce the lifespan of infected cells $(32,33)$; or ii) that more detailed models of the viral lifecycle, for example including an eclipse phase before viral production $(32,33,72)$ or an exponential increase in viral production (73), could be compatible with the data and with an important cytolytic effect.

In support of the first explanation, there are many experimental observations that are consistent with a non-cytolytic effect of CD8+ T cells. In this context, multiple soluble factors have been found or proposed to reduce viral replication (reviewed in (11)). Indeed, the possibility of a non-lytic effect was also the conclusion of one of the first studies of chronically SIV-infected macaques depleted of CD8+ cells described above (27), where it was found that an effect in viral production was more consistent with the data. Moreover, a re-analysis of the experimental data by Klatt et al. comparing models with cytolytic and noncytolytic effects concluded that the latter had more support (74). Modeling data on rates of escape from CD8+ T cells in SIV infection also indicated that the observations were more consistent with non-cytolytic effects (75). One issue with the hypothesis of non-cytolytic effects is that if these are mediated by soluble factors, then they may not be strain/epitope specific and thus would not be able to drive viral escape from CD8 responses. However, another modeling study showed that there are conditions when non-cytolytic responses can also drive specific mutations escaping CD8-mediated control (76).

A different explanation for the similarity of decay rates of virus in monkeys depleted of CD8+ cells or not, and treated with antiretroviral therapy is that the lifecycle of SIV is more complex than the way it was modeled in the original studies. As an example, any cytolytic effects could occur before infected cells start producing virus $(32,33,64,72,77)$. The lifecycle of HIV proceeds through multiple steps (7), from binding and fusion of the viral 
envelope with the target-cell plasma membrane; through reverse transcription of the viral RNA into proviral DNA and its integration into the host-cell genome. It is only after this integration step that viral production can start. Indeed, studies of the viral life cycle indicate that more than half of the lifespan of an infected cell corresponds to events between cell entry and viral production $(78,79)$. Moreover, experimental observations show that viral epitopes are expressed on the surface of the infected cell very early on $(80,81)$ and that later there is viral-induced MHC down-regulation from the surface of infected cells, through the action of the HIV nef protein (82-84), making CTL targeting less efficient (85). These two facts support the notion that immune-mediated killing of infected cells could occur early, before the cells start producing virus, and thus that CD8+ T-cells could have important cytolytic activity.

Figure 5 shows a diagram of a model of the HIV lifecycle with multiple phases. In a multiphase model, interruption of viral replication with antiretroviral therapy results in viral decay with a slope corresponding to the slowest phase of the lifecycle $(64,86-88)$. If any (or most of the) cytolytic effect of CD8+ cells occurred during a fast phase of the lifecycle, depletion of these cells would not have an impact on the viral decay slope during therapy. Indeed, this slope, with or without CD8+ cells, would always reflect the rate of the slowest phase. This was studied in great detail and elegance in a recent paper by Gadhamsetty et al. (64), where they concluded that although not proving that CD8+ cells had a cytolytic mechanism of action, "we have shown that all experiments that were previously taken to favor nonlytic control by CD8+ T cells are perfectly consistent with a pure cytotoxic mechanism of control".

Another proposal to reconcile a cytolytic mechanism with the observation of no decrease in productively infected cell lifespan was based on the idea that viral production is likely not constant, but increases over time since infection (73). In this model, viral production by infected cells increases exponentially after an eclipse phase and cytolytic activity is present throughout, but also increasing with time since infection. The authors showed that such a model could reproduce the previous experimental results, because it only predicted small differences in the slopes of decay of viral load in depleted vs. non-depleted animals (73). In this scenario, immune-mediated killing would occur just before the cells would die from viral cytopathic effects (86) and thus would not shorten the lifespan by much. These differences would be too small to be detectable in the experiments due to the variability in slopes from animal to animal and the relatively small numbers of macaques studied. Interestingly a prior study already addressed the issue of statistical power to detect differences in infected cell lifespan in the (necessary small-sample) animal studies (74). The authors concluded that it was possible that a lytic effect would be small and not observable in the experiments (74).

In conclusion, the relatively simple and straightforward interpretation of CD8+ cell depletion experiments in the context of ART therapy, i.e., that the main effect of those cells is to control viral replication by non-cytolytic mechanisms, may not be the only possible one. It, in fact, also depends on the simple one-compartment model used to analyze the viral load decay. 


\section{TREATMENT WITH INTEGRASE INHIBITORS AND CD8+ CELL DEPLETION}

\subsection{DYNAMICS OF VIRAL LOAD UNDER INTEGRASE INHIBITOR THERAPY}

The CD8+ cell depletion and treatment experiments discussed $(32,33)$ used the same antiretroviral therapy protocol based on a combination of reverse transcriptase inhibitors (RTI). These drugs block viral replication early in the viral lifecycle and lead to a single exponential decay of viral load early after treatment is started, which corresponds, as mentioned above, to the slower of any subsequent stages of the lifecycle $(64,86-88)$. In addition, to interpret CD8+ cell depletion experiments, it is often assumed that cytolytic activity occurs at some stage after the step blocked by treatment (64), in this case reverse transcription.

Studies modeling the viral load decline in chronically infected patients treated with regimens containing the integrase strand transfer inhibitor (InSTI) raltegravir (RAL), which affects a stage of the virus life cycle after reverse transcription, show a pattern of virus decline very distinct from previous studies with RTIs (13-16). Two recent modeling studies analyzed the viral load decline in two sets of infected patients receiving RAL, in one case treatment was monotherapy for a period of 9 days (15), and in the other infected individuals received RTIs and RAL, with frequent sampling of the viral load over the first 28 days of treatment (14). In both studies, plasma viral load decline during the first 10 days of therapy presented an early fast phase of decay (phase 1a) followed by a slower phase of decay (phase 1b) (13). Phase 1a has a decay rate of $\sim 1$ /day very similar to the initial decline in viral load in HIV-infected individuals under ART without an InSTI. Phase $1 \mathrm{~b}$ had a slower rate of about 0.2 /day, and is absent under ART without InSTI $(19,20)$ (see Fig. 6).

To understand this viral kinetics, accounting for the effect of RAL, several authors added to the standard model an early phase of average duration $1 / k$ (Fig. 5) $(64,72,87-90)$. During this early phase (sometimes called an eclipse phase), infected cells do not produce virus and die at rate $\delta_{1}$. After integration, infected cells are able to produce new virus and die at rate $\delta_{2}$ $(64,72,89-91)$. The effect of RAL is included in the model by reducing the integration rate $k$ by a factor $(1-\omega)$, where $\omega$ is the efficacy of $\operatorname{RAL}(89,90,92)$. The equations for this model are

$$
\begin{aligned}
& \frac{d T}{d t}=\lambda-d T-\beta V T \\
& \frac{d I_{1}}{d t}=\beta V T-\delta_{1} I_{1}-k(1-\omega) I_{1} \\
& \frac{d I_{2}}{d t}=k(1-\omega) I_{1}-\delta_{2} I_{2} \\
& \frac{d V}{d t}=p I_{2}-c V
\end{aligned}
$$

Using this model, the observed viral decay with two early phases during therapy with RAL, but only one phase in the absence of RAL, is predicted if the loss of productively infected 
cells is slower than the loss of non-productively infected cells (i.e., if $\delta_{2}<<\delta_{1}+k$ ) without RAL, but this relationship is reversed in the presence of RAL (i.e., if $\left.\delta_{2} \gg \delta_{1}+k(1-\omega)\right)(89$, 90). This model is similar to the one proposed by Gadhamsetty et al. (64), but treatment with the integrase inhibitor occurs at a later stage of infection than with RTIs, and crucially treatment reverses what is the slow and the fast phases of the lifecycle.

\subsection{PREDICTIONS OF VIRAL DECLINE UNDER RAL THERAPY AND CD8+ CELL DEPLETION}

In the context of model (3), if CD8+ cells kill productively infected cells, $I_{2}$, then phase $1 \mathrm{a}$ should reflect the sum of the intrinsic death and the CD8+ cell-mediated death, i.e. $\delta_{2}=$ $\mathrm{d}_{2}+\Phi_{2}$. Similarly, if CD8+ cells kill non-productively infected cells, $I_{1}$, then phase $1 \mathrm{~b}$ reflects the sum of the intrinsic death of these cells and the CD8+ cell-mediated death, i.e. $\delta_{1}$ $=\mathrm{d}_{1}+\Phi_{1}$. Multiple studies have shown that when treatment interferes with a step of the lifecycle early in infection, such that there are multiple stages later then the observed viral load decay corresponds to the slowest time-scale among those stages $(64,72,87,88)$. However, integrase inhibitor therapy affects a step that is relatively late in the viral lifecycle (79), soon before the infected cell becomes productive. As such, it is not clear what would be the prediction for a $\mathrm{CD} 8+$ cell depletion experiments in the context of this therapy.

To understand how the inclusion of RAL may clarify CD8+ cells effector mechanisms, we can use model (3) above to simulate the two possibilities (in the model) for the cytolytic effect of CD8+ cells in infected animals. In the first case, CD8+ cells kill productively infected cells, $I_{2}$; and in the second case, they kill non-productively infected cells, $I_{1}$. In the first case, the death of productively infected cells is $d_{2}+\Phi_{2}$ before CD8+ cell depletion and $d_{2}$ after. Similarly, in the second case, the death of non-productively infected cells is $d_{1}+\Phi_{1}$ before CD8 depletion and $d_{1}$ after. We assume that the CD8+ cell killing rates, $\Phi_{1}$ and $\Phi_{2}$, are smaller than 0.2 and 1 day $^{-1}$, respectively, because these are the observed slopes of phases 1b and 1a, respectively. Depletion of CD8+ cells is simulated by setting $\Phi_{1}$ or $\Phi_{2}$ equal to zero. Finally, therapy with RAL (in the presence or absence of CD8+ cells) is include as before, by multiplying the rate of integration, $k$, by $(1-\omega)$, where $\omega$ is the efficacy of RAL, with $0 \leq \omega \leq 1$. For illustration purposes, the parameter values used are those estimated in previous studies (Fig. 7 and $(89,90)$ ).

Figure 7 present schematics of the results predicted for CD8+ cell-depletion and RAL therapy. When CD8+ effector cells kill productively infected cells, $I_{2}$, (Fig. 7A-B), there is a difference in the slope of viral decay between depleted (green) and non-depleted (red) states for both ART with and without RAL. This recapitulates results presented before (64) when $\delta_{2}<<\delta_{1}+k$ and is inconsistent with experimental observations $(32,33)$, because the observed decay of virus with RTI therapy is the same with and without CD8+ cells (Fig. 4C). On the other hand, the effect of CD8+ cells killing non-productively infected cells, $I_{1}$, is depicted in Figures 7C-D. In this case, treatment with RTIs (without RAL) leads to similar viral load declines in the presence or absence of CD8+ cells (Fig. 7C), in perfect agreement with experimental observations $(32,33)$. However, in the case of therapy with RAL, a clear difference can be observed in phase $1 \mathrm{~b}$ of the viral load decline in the presence or absence of CD8+ cells (red and blue, respectively, in Fig. 7D). This difference is more noticeable if the 
intrinsic death rate, $d_{1}$, of non-productively infected cells, $I_{1}$, is small, so that $\Phi_{1}$ is closer to 0.2 day $^{-1}$.

We have developed an experimental protocol similar to this one for CD8+ cell-depletion and RAL therapy in non-human primates (63). Preliminary results indicate a difference in the slopes of viral decline with RAL therapy in the presence vs. absence of CD8+ cells (Ribeiro et al. unpublished observations). Whether these results are in agreement with the schematic results predicted by the modeling and depicted in Figure 7 is still under investigation.

\section{CONCLUSIONS}

HIV infection is still one of the largest causes of morbidity and mortality across the globe. More than 35 years after it first appeared on the world stage, our knowledge of its pathogenesis, immune impairment and control is perhaps unparalleled with any other infection. At the same time, there are basic questions that still remain unanswered. One of these is what are the exact mechanisms of action of CD8+ T cells? One way to analyze this question has been to perform CD8+ cell depletion experiments. Interpretation of these experiments, towards mechanistic insights, requires the use of mathematical modeling. Indeed, it is a prime example of how to apply modeling to biological data, including the importance of decisions on what model to use, scrutiny of assumptions, data fitting, interpretation of results, and suggestion of new experiments. Although it has been almost 20 years since this type of experiments were first reported, there is still no consensus on the exact meaning of the experimental observations. Indeed, a very recent new result cast an unexpected twist that will need further investigation. Using a new antibody that depletes CD8 $\beta+$ cells (and not CD8 $a+$ cells, as in previous studies), Martins et al. (56) found in at least one animal that depletion of $\mathrm{CD} 8 \beta+$ cells had no impact on viral load, while in the same animal depletion of CD8a+ cells led to the well-known rapid increase in viral load.

The main conclusion is, thus, that understanding the mechanisms of CD8+ T-cell action in HIV infection is still an open question with ongoing investigation.

\section{ACKNOWLEDGEMENTS}

We thank Chowdhury et al. (41) for sharing the viral load data of their publication with us.

This work was supported by the National Institutes of Health/National Center for Research Resources/National Institute of Allergy and Infectious Diseases/National Heart, Lung and Blood Institute grants AI104373 (RMR), R01 HL117715 (IP), AI119346 (CA), HL123096 (IP) and DK113919 (IP and CA). EFC is supported by a grant from the National Institutes of Health, National Institute of Allergy and Infectious Diseases (UM1 AI126623). The funders had no role in study design, data collection and analysis, decision to publish, or preparation of the manuscript.

\section{REFERENCES}

1. Robb ML, Eller LA, Kibuuka H, et al. Prospective Study of Acute HIV-1 Infection in Adults in East Africa and Thailand. N. Engl. J. Med 2016; 374: 2120-2130. [PubMed: 27192360]

2. Geskus RB, Prins M, Hubert J-B, et al. The HIV RNA setpoint theory revisited. Retrovirology 2007; 4: 65. [PubMed: 17888148] 
3. He T, Falwell E, Brocca-Cofano E, Pandrea I. Modeling aging in HIV infection in nonhuman primates to address an emerging challenge of the post-ART era. Curr. Opin. Virol 2017; 25: 66-75. [PubMed: 28803049]

4. Pandrea I, Landay A, Wilson C, Stock J, Tracy R, Apetrei C. Using the Pathogenic and Nonpathogenic Nonhuman Primate Model for Studying Non-AIDS Comorbidities. Curr. HIV/AIDS Rep 2015; 12: 54-67. [PubMed: 25604236]

5. Deeks SG, Lewin SR, Havlir DV. The end of AIDS: HIV infection as a chronic disease. The Lancet 2013; 382: 1525-1533.

6. Hütter G, Nowak D, Mossner M, et al. Long-Term Control of HIV by CCR5 Delta32/Delta32 StemCell Transplantation. N. Engl. J. Med 2009; 360: 692-698. [PubMed: 19213682]

7. Levy JA. HIV and the Pathogenesis of AIDS, Third Edition. American Society of Microbiology, 2007.

8. Lechner F, Cuero ALV, Kantzanou M, Klenerman P. Studies of human antiviral CD8+ lymphocytes using class I peptide tetramers. Rev. Med. Virol 2001; 11: 11-22. [PubMed: 11241799]

9. Lauer GM, Nguyen TN, Day CL, et al. Human Immunodeficiency Virus Type 1-Hepatitis C Virus Coinfection: Intraindividual Comparison of Cellular Immune Responses against Two Persistent Viruses. J. Virol 2002; 76: 2817-2826. [PubMed: 11861849]

10. Fourcade L, Poudrier J, Roger M. Natural Immunity to HIV: A Template for Vaccine Strategies. Viruses 2018; 10: 215.

11. McBrien JB, Kumar NA, Silvestri G. Mechanisms of CD8+ T cell-mediated suppression of HIV/SIV replication. Eur. J. Immunol 0:

12. Koup RA, Safrit JT, Cao Y, et al. Temporal association of cellular immune responses with the initial control of viremia in primary human immunodeficiency virus type 1 syndrome. J. Virol 1994; 68: 4650-4655. [PubMed: 8207839]

13. Carrington M, O’Brien SJ. The Influence of HLA Genotype on AIDS. Annu. Rev. Med 2003; 54 : 535-551. [PubMed: 12525683]

14. Fellay J, Shianna KV, Ge D, et al. A Whole-Genome Association Study of Major Determinants for Host Control of HIV-1. Science 2007; 317: 944-947. [PubMed: 17641165]

15. Goulder PJR, Watkins DI. HIV and SIV CTL escape: implications for vaccine design. Nat. Rev. Immunol 2004; 4: 630-640. [PubMed: 15286729]

16. McMichael AJ, Borrow P, Tomaras GD, Goonetilleke N, Haynes BF. The immune response during acute HIV-1 infection: clues for vaccine development. Nat. Rev. Immunol 2010; 10: 11-23. [PubMed: 20010788]

17. Kawashima Y, Pfafferott K, Frater J, et al. Adaptation of HIV-1 to human leukocyte antigen class I. Nature 2009; 458: 641-645. [PubMed: 19242411]

18. Lieberman J, Skolnik PR, Parkerson GR, et al. Safety of Autologous, Ex Vivo-Expanded Human Immunodeficiency Virus (HIV)-Specific Cytotoxic T-Lymphocyte Infusion in HIV-Infected Patients. Blood 1997; 90: 2196-2206. [PubMed: 9310470]

19. Chea S, Dale CJ, Rose RD, Ramshaw IA, Kent SJ. Enhanced Cellular Immunity in Macaques following a Novel Peptide Immunotherapy. J. Virol 2005; 79: 3748-3757. [PubMed: 15731268]

20. Minang JT, Trivett MT, Bolton DL, et al. Distribution, Persistence, and Efficacy of Adoptively Transferred Central and Effector Memory-Derived Autologous Simian Immunodeficiency VirusSpecific CD8+ T Cell Clones in Rhesus Macaques during Acute Infection. J. Immunol 2010; 184 : 315-326. [PubMed: 19949091]

21. Mohns MS, Greene JM, Cain BT, et al. Expansion of Simian Immunodeficiency Virus (SIV)Specific CD8 T Cell Lines from SIV-Naive Mauritian Cynomolgus Macaques for Adoptive Transfer. J. Virol 2015; 89: 9748-9757. [PubMed: 26178985]

22. Ayala VI, Trivett MT, Barsov EV, et al. Adoptive transfer of engineered rhesus SIV-specific CD8+ $\mathrm{T}$ cells reduces the number of transmitted/founder viruses established in rhesus macaques. J. Virol 2016; 90: 9942-9952. [PubMed: 27558423]

23. Bolton DL, Minang JT, Trivett MT, et al. Trafficking, persistence, and activation state of adoptively transferred allogeneic and autologous simian immunodeficiency virus-specific CD8+ T cell clones during acute and chronic infection of rhesus macaques. J. Immunol 2010; 184: 303-314. [PubMed: 19949089] 
24. Chapuis AG, Desmarais C, Emerson R, et al. Tracking the fate and origin of clinically relevant adoptively transferred CD8+ T cells in vivo. Sci. Immunol 2017; 2: eaal2568. [PubMed: 28367538]

25. Davenport MP, Ribeiro RM, Perelson AS. Kinetics of Virus-Specific CD8+ T Cells and the Control of Human Immunodeficiency Virus Infection. J. Virol 2004; 78: 10096-10103. [PubMed: 15331742]

26. Koup RA, Douek DC. Vaccine Design for CD8 T Lymphocyte Responses. Cold Spring Harb. Perspect. Med 2011; 1: a007252. [PubMed: 22229122]

27. Jin X, Bauer DE, Tuttleton SE, et al. Dramatic Rise in Plasma Viremia after CD8+ T Cell Depletion in Simian Immunodeficiency Virus-infected Macaques. J. Exp. Med 1999; 189: 991998. [PubMed: 10075982]

28. Schmitz JE, Kuroda MJ, Santra S, et al. Control of viremia in simian immunodeficiency virus infection by CD8+ lymphocytes. Science 1999; 283: 857-860. [PubMed: 9933172]

29. Phillips AN. Reduction of HIV Concentration During Acute Infection: Independence from a Specific Immune Response. Science 1996; 271: 497-499. [PubMed: 8560262]

30. Spits HB, Mudrikova T, Schellens IM m, et al. The presence of protective cytotoxic T lymphocytes does not correlate with shorter lifespans of productively infected cells in Hiv-1 infection. Aids 2016; 30: 9-17. [PubMed: 26731751]

31. Kilby JM, Lee HY, Hazelwood JD, et al. Treatment response in acute/early infection versus advanced Aids: equivalent first and second phases of Hiv Rna decline. Aids 2008; 22: 957-962. [PubMed: 18453855]

32. Klatt NR, Shudo E, Ortiz AM, et al. CD8+ lymphocytes control viral replication in SIVmac239infected rhesus macaques without decreasing the lifespan of productively infected cells. PLoS Pathog 2010; 6: e1000747. [PubMed: 20126441]

33. Wong JK, Strain MC, Porrata R, et al. In Vivo CD8+ T-Cell Suppression of SIV Viremia Is Not Mediated by CTL Clearance of Productively Infected Cells. PLoS Pathog 2010; 6: e1000748. [PubMed: 20126442]

34. Eisener-Dorman AF, Lawrence DA, Bolivar VJ. Cautionary insights on knockout mouse studies: The gene or not the gene? Brain. Behav. Immun 2009; 23: 318-324. [PubMed: 18822367]

35. Schmitz JE, Simon MA, Kuroda MJ, et al. A Nonhuman Primate Model for the Selective Elimination of CD8+ Lymphocytes Using a Mouse-Human Chimeric Monoclonal Antibody. Am. J. Pathol 1999; 154: 1923-1932. [PubMed: 10362819]

36. Available Reagents - NIH Nonhuman Primate Reagent Resource.

37. Madden LJ, Zandonatti MA, Flynn CT, et al. CD8+ cell depletion amplifies the acute retroviral syndrome. J. Neurovirol. 2004; 10: 58-66. [PubMed: 14982741]

38. Okoye A, Park H, Rohankhedkar M, et al. Profound CD4+/CCR5+ T cell expansion is induced by CD8+ lymphocyte depletion but does not account for accelerated SIV pathogenesis. J. Exp. Med 2009; 206: 1575-1588. [PubMed: 19546246]

39. Matano T, Shibata R, Siemon C, Connors M, Lane HC, Martin MA. Administration of an AntiCD8 Monoclonal Antibody Interferes with the Clearance of Chimeric Simian/Human Immunodeficiency Virus during Primary Infections of Rhesus Macaques. J. Virol 1998; 72: 164169. [PubMed: 9420212]

40. Mueller YM, Do DH, Boyer JD, et al. CD8+ Cell Depletion of SHIV89.6P-Infected Macaques Induces CD4+ T Cell Proliferation that Contributes to Increased Viral Loads. J. Immunol 2009; 183: 5006-5012. [PubMed: 19786539]

41. Chowdhury A, Hayes TL, Bosinger SE, et al. Differential Impact of In Vivo CD8+ T Lymphocyte Depletion in Controller versus Progressor Simian Immunodeficiency Virus-Infected Macaques. J. Virol 2015; 89: 8677-8686. [PubMed: 26063417]

42. Bosinger SE, Jochems SP, Folkner KA, Hayes TL, Klatt NR, Silvestri G. Transcriptional profiling of experimental CD8+ lymphocyte depletion in rhesus macaques infected with simian immunodeficiency virus SIVmac239. J. Virol 2013; 87: 433-443. [PubMed: 23097439]

43. Soulas C, Autissier PJ, Burdo TH, Jr MP, Lifson JD, Williams KC. Distinct Phenotype, Longitudinal Changes of Numbers and Cell-Associated Virus in Blood Dendritic Cells in SIV- 
Infected CD8-Lymphocyte Depleted Macaques. PLOS ONE 2015; 10: e0119764. [PubMed: 25915601]

44. Li S, Folkvord JM, Rakasz EG, et al. Simian Immunodeficiency Virus-Producing Cells in Follicles Are Partially Suppressed by CD8+ Cells In Vivo. J. Virol 2016; 90: 11168-11180. [PubMed: 27707919]

45. Veazey RS, Acierno PM, McEvers KJ, et al. Increased Loss of CCR5+ CD45RA- CD4+ T Cells in CD8+ Lymphocyte-Depleted Simian Immunodeficiency Virus-Infected Rhesus Monkeys. J. Virol 2008; 82: 5618-5630. [PubMed: 18367534]

46. Magalis BR, Nolan DJ, Autissier P, Burdo TH, Williams KC, Salemi M. Insights into the Impact of CD8+ Immune Modulation on Human Immunodeficiency Virus Evolutionary Dynamics in Distinct Anatomical Compartments by Using Simian Immunodeficiency Virus-Infected Macaque Models of AIDS Progression. J. Virol 2017; 91: e01162-17. [PubMed: 28931681]

47. Cartwright EK, Spicer L, Smith SA, et al. CD8+ Lymphocytes Are Required for Maintaining Viral Suppression in SIV-Infected Macaques Treated with Short-Term Antiretroviral Therapy. Immunity 2016; 45: 656-668. [PubMed: 27653601]

48. Gaufin T, Ribeiro RM, Gautam R, et al. Experimental depletion of CD8+ cells in acutely SIVagmInfected African Green Monkeys results in increased viral replication. Retrovirology 2010; 7: 42. [PubMed: 20459829]

49. Zahn RC, Rett MD, Li M, et al. Suppression of adaptive immune responses during primary SIV infection of sabaeus African green monkeys delays partial containment of viremia but does not induce disease. Blood 2010; 115: 3070-3078. [PubMed: 20147699]

50. Schmitz JE, Zahn RC, Brown CR, et al. Inhibition of Adaptive Immune Responses Leads to a Fatal Clinical Outcome in SIV-Infected Pigtailed Macaques but Not Vervet African Green Monkeys. PLOS Pathog. 2009; 5: e1000691. [PubMed: 20011508]

51. Barry AP, Silvestri G, Safrit JT, et al. Depletion of CD8+ Cells in sooty mangabey monkeys naturally infected with simian immunodeficiency virus reveals limited role for immune control of virus replication in a natural host species. J. Immunol 2007; 178: 8002-8012. [PubMed: 17548637]

52. Metzner KJ, Jin X, Lee FV, et al. Effects of in Vivo Cd8+ T Cell Depletion on Virus Replication in Rhesus Macaques Immunized with a Live, Attenuated Simian Immunodeficiency Virus Vaccine. J. Exp. Med 2000; 191: 1921-1932. [PubMed: 10839807]

53. Schmitz JE, Johnson RP, McClure HM, et al. Effect of CD8+ Lymphocyte Depletion on Virus Containment after Simian Immunodeficiency Virus SIVmac251 Challenge of Live Attenuated SIVmac23943-Vaccinated Rhesus Macaques. J. Virol 2005; 79: 8131-8141. [PubMed: 15956558]

54. Gegerfelt A von, Valentin A, Alicea C, et al. Emergence of Simian Immunodeficiency VirusSpecific Cytotoxic CD4+ T Cells and Increased Humoral Responses Correlate with Control of Rebounding Viremia in CD8-Depleted Macaques Infected with Rev-Independent Live-Attenuated Simian Immunodeficiency Virus. J. Immunol 2010; 185: 3348-3358. [PubMed: 20702730]

55. Stebbings R, Berry N, Waldmann H, et al. CD8+ Lymphocytes Do Not Mediate Protection against Acute Superinfection 20 Days after Vaccination with a Live Attenuated Simian Immunodeficiency Virus. J. Virol 2005; 79: 12264-12272. [PubMed: 16160152]

56. Martins MA, Tully DC, Shin YC, et al. Rare Control of SIVmac239 Infection in a Vaccinated Rhesus Macaque. AIDS Res. Hum. Retroviruses 2017; 33: 843-858. [PubMed: 28503929]

57. Hansen SG, Ford JC, Lewis MS, et al. Profound early control of highly pathogenic SIV by an effector memory T-cell vaccine. Nature 2011; 473: 523-527. [PubMed: 21562493]

58. Schell JB, Rose NF, Bahl K, et al. Significant Protection against High-Dose Simian Immunodeficiency Virus Challenge Conferred by a New Prime-Boost Vaccine Regimen. J. Virol 2011; 85: 5764-5772. [PubMed: 21490100]

59. Reynolds MR, Weiler AM, Weisgrau KL, et al. Macaques vaccinated with live-attenuated SIV control replication of heterologous virus. J. Exp. Med 2008; 205: 2537-2550. [PubMed: 18838548]

60. Williams K, Lackner A, Mallard J. Non-human primate models of SIV infection and CNS neuropathology. Curr. Opin. Virol 2016; 19: 92-98. [PubMed: 27544476] 
61. Ratai E-M, Pilkenton S, He J, et al. CD8+ lymphocyte depletion without SIV infection does not produce metabolic changes or pathological abnormalities in the rhesus macaque brain. J. Med. Primatol 2011; 40: 300-309. [PubMed: 21463330]

62. Mankowski JL, Clements JE, Zink MC. Searching for Clues: Tracking the Pathogenesis of Human Immunodeficiency Virus Central Nervous System Disease by Use of an Accelerated, Consistent Simian Immunodeficiency Virus Macaque Model. J. Infect. Dis 2002; 186: S199-S208. [PubMed: 12424698]

63. Policicchio BB, Cardozo EF, Sette P, et al. The dynamics of SIV 2-LTR Circles in the Presence and Absence of CD8+ Cells. J. Virol 2018; JVI.02100-17.

64. Gadhamsetty S, Coorens T, Boer RJ de. Notwithstanding Circumstantial Alibis, Cytotoxic T Cells Can Be Major Killers of HIV-1-Infected Cells. J. Virol 2016; 90: 7066-7083. [PubMed: 27226367]

65. Lifson JD, Rossio JL, Piatak M, et al. Role of CD8+ Lymphocytes in Control of Simian Immunodeficiency Virus Infection and Resistance to Rechallenge after Transient Early Antiretroviral Treatment. J. Virol 2001; 75: 10187-10199. [PubMed: 11581387]

66. Friedrich TC, Valentine LE, Yant LJ, et al. Subdominant CD8+ T-Cell Responses Are Involved in Durable Control of AIDS Virus Replication. J. Virol 2007; 81: 3465-3476. [PubMed: 17251286]

67. Fukazawa Y, Lum R, Okoye AA, et al. B cell follicle sanctuary permits persistent productive simian immunodeficiency virus infection in elite controllers. Nat. Med 2015; 21: 132-139. [PubMed: 25599132]

68. Pandrea I, Gaufin T, Gautam R, et al. Functional Cure of SIVagm Infection in Rhesus Macaques Results in Complete Recovery of CD4+ T Cells and Is Reverted by CD8+ Cell Depletion. PLOS Pathog. 2011; 7: e1002170. [PubMed: 21829366]

69. Amara RR, Ibegbu C, Villinger F, et al. Studies using a viral challenge and CD8 T cell depletions on the roles of cellular and humoral immunity in the control of an SHIV-89.6P challenge in DNA/ MVA-vaccinated macaques. Virology 2005; 343: 246-255. [PubMed: 16185742]

70. Nishimura Y, Gautam R, Chun T-W, et al. Early antibody therapy can induce long-lasting immunity to SHIV. Nature 2017; 543: 559-563. [PubMed: 28289286]

71. Mittler JE, Sulzer B, Neumann AU, Perelson AS. Influence of delayed viral production on viral dynamics in HIV-1 infected patients. Math. Biosci 1998; 152: 143-163. [PubMed: 9780612]

72. Althaus CL, Boer RJD. Implications of CTL-mediated killing of HIV-infected cells during the nonproductive stage of infection. PLOS ONE 2011; 6: e16468. [PubMed: 21326882]

73. Wick WD, Yang OO. Biologically-Directed Modeling Reflects Cytolytic Clearance of SIVInfected Cells In Vivo in Macaques. PLOS ONE 2012; 7: e44778. [PubMed: 23028619]

74. Elemans M, Basatena N-KS al, Klatt NR, Gkekas C, Silvestri G, Asquith B. Why Don't CD8+ T Cells Reduce the Lifespan of SIV-Infected Cells In Vivo? PLOS Comput. Biol 2011; 7: e1002200. [PubMed: 21990968]

75. Balamurali M, Petravic J, Loh L, Alcantara S, Kent SJ, Davenport MP. Does cytolysis by CD8+ T cells drive immune escape in HIV infection? J. Immunol 2010; 185: 5093-5101. [PubMed: 20881189]

76. Basatena N-KS al, Chatzimichalis K, Graw F, Frost SDW, Regoes RR, Asquith B. Can non-lytic CD8+ T cells drive HIV-1 escape? PLOS Pathog. 2013; 9: e1003656. [PubMed: 24244151]

77. Davenport MP, Ribeiro RM, Zhang L, Wilson DP, Perelson AS. Understanding the mechanisms and limitations of immune control of HIV. Immunol. Rev 216: 164-175. [PubMed: 17367342]

78. Murray JM, Kelleher AD, Cooper DA. Timing of the Components of the HIV Life Cycle in Productively Infected CD4+ T Cells in a Population of HIV-Infected Individuals. J. Virol 2011; 85: 10798-10805. [PubMed: 21835801]

79. Mohammadi P, Desfarges S, Bartha I, et al. 24 Hours in the Life of HIV-1 in a T Cell Line. PLOS Pathog. 2013; 9: e1003161. [PubMed: 23382686]

80. Sacha JB, Chung C, Rakasz EG, et al. Gag-Specific CD8+ T Lymphocytes Recognize Infected Cells before AIDS-Virus Integration and Viral Protein Expression. J. Immunol. 2007; 178: 27462754. [PubMed: 17312117] 
81. Sacha JB, Buechler MB, Newman LP, et al. Simian Immunodeficiency Virus-Specific CD8+ T Cells Recognize Vpr- and Rev-Derived Epitopes Early after Infection. J. Virol 2010; 84: 1090710912. [PubMed: 20686015]

82. Kerkau T, Gernert S, Kneitz C, Schimpl A. Mechanism of MHC Class I Downregulation in HIV Infected Cells. Immunobiology 1992; 184: 402-409. [PubMed: 1350567]

83. Schwartz O, Maréchal V, Gall SL, Lemonnier F, Heard J-M. Endocytosis of major histocompatibility complex class I molecules is induced by the HIV-1 Nef protein. Nat. Med 1996; 2: 338-342. [PubMed: 8612235]

84. Dirk BS, Pawlak EN, Johnson AL, et al. HIV-1 Nef sequesters MHC-I intracellularly by targeting early stages of endocytosis and recycling. Sci. Rep 2016; 6: 37021. [PubMed: 27841315]

85. Collins KL, Chen BK, Kalams SA, Walker BD, Baltimore D. HIV-1 Nef protein protects infected primary cells against killing by cytotoxic T lymphocytes. Nature 1998; 391: 397-401. [PubMed: 9450757]

86. Klenerman P, Phillips RE, Rinaldo CR, et al. Cytotoxic T lymphocytes and viral turnover in HIV type 1 infection. Proc. Natl. Acad. Sci 1996; 93: 15323-15328. [PubMed: 8986810]

87. Gilmore JB, Kelleher AD, Cooper DA, Murray JM. Explaining the Determinants of First Phase HIV Decay Dynamics through the Effects of Stage-dependent Drug Action. PLOS Comput. Biol 2013; 9: e1002971. [PubMed: 23555209]

88. Wang X, Song X, Tang S, Rong L. Dynamics of an HIV Model with Multiple Infection Stages and Treatment with Different Drug Classes. Bull. Math. Biol 2016; 78: 322-349. [PubMed: 26842389]

89. Andrade A, Guedj J, Rosenkranz SL, et al. Early HIV RNA decay during raltegravir-containing regimens exhibits two distinct subphases (1a and 1b). AIDS 2015; 29: 2419-2426. [PubMed: 26558541]

90. Cardozo EF, Andrade A, Mellors JW, Kuritzkes DR, Perelson AS, Ribeiro RM. Treatment with integrase inhibitor suggests a new interpretation of HIV RNA decay curves that reveals a subset of cells with slow integration. PLOS Pathog. 2017; 13: e1006478. [PubMed: 28678879]

91. Gadhamsetty S, Beltman JB, Boer RJ de. What do mathematical models tell us about killing rates during HIV-1 infection? Immunol. Lett 2015; 168: 1-6. [PubMed: 26279491]

92. Sedaghat AR, Siliciano RF, Wilke CO. Constraints on the dominant mechanism for HIV viral dynamics in patients on raltegravir. Antivir. Ther 2009; 14: 263-271. [PubMed: 19430101] 
A.

SIVmac239 or

SIVmac251

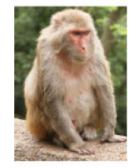

challenge

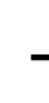

$\frac{1}{\text { Tim }}$

Time until chronic

infection

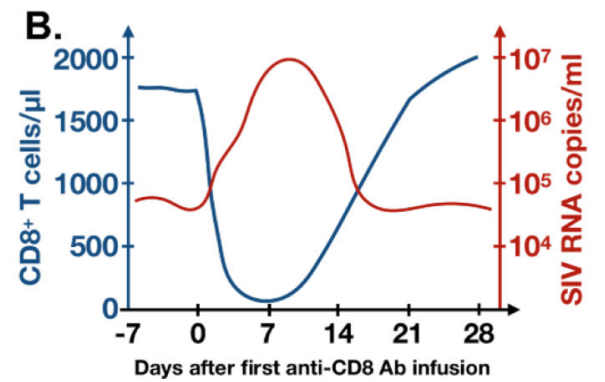

Figure 1. Schematic of a CD8-depletion experiment.

(A) Timeline of the infection challenge and anti-CD8 antibody infusion. (B) Representation of CD8+ T cell counts and viral loads during the depletion, which starts at day 0. Macaque photo from https://www.flickr.com/photos/wild_speedy/4185543087/, under a Creative Commons CC BY-SA 2.0 license (https://creativecommons.org/licenses/by-sa/2.0/). 
A.

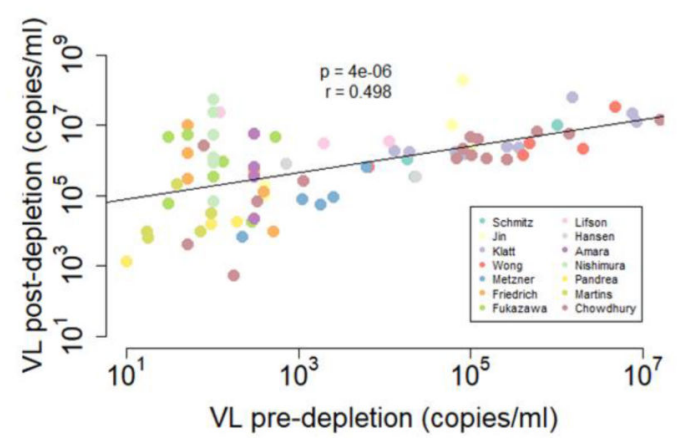

B.

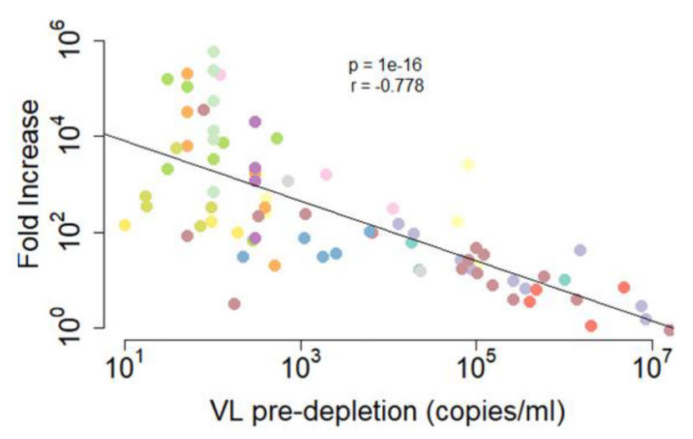

Figure 2. Correlation of viral load pre-depletion with (A) peak viral load post-depletion and (B) fold-increase during depletion.

The strength and significance of the Spearman rank correlation are shown. See Table 1 for the description of the studies and corresponding references. The data presented was digitized for most of the studies, with the exception of our own and (41), for which we have the original data. 
A.

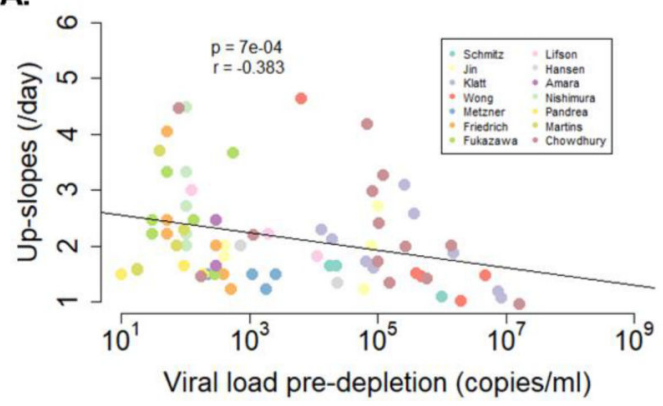

B.

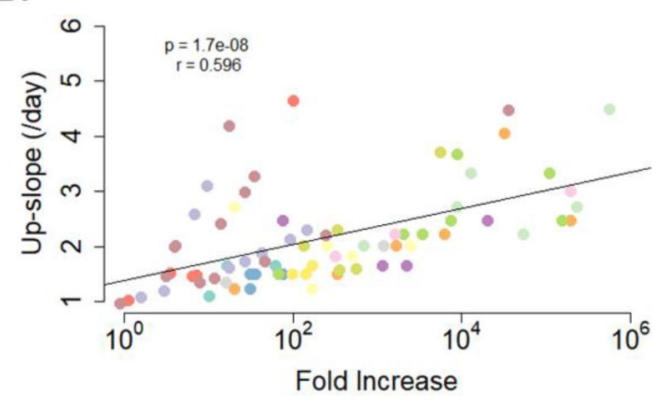

Figure 3. Correlation of viral load up-slopes during depletion with (A) viral load pre-depletion and (B) fold-increase during depletion.

The strength and significance of the Spearman rank correlation are shown. See Table 1 for the description of the studies and corresponding references. Note: three outliers with slope larger than 8/day are not shown. 
A.

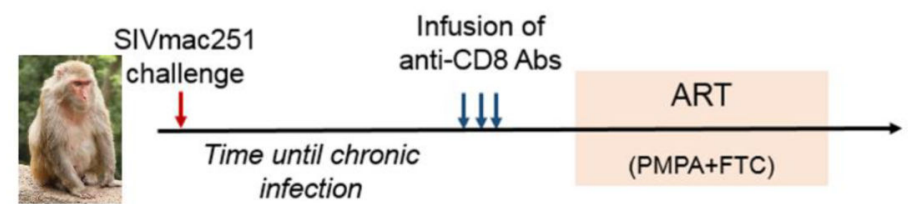

B.

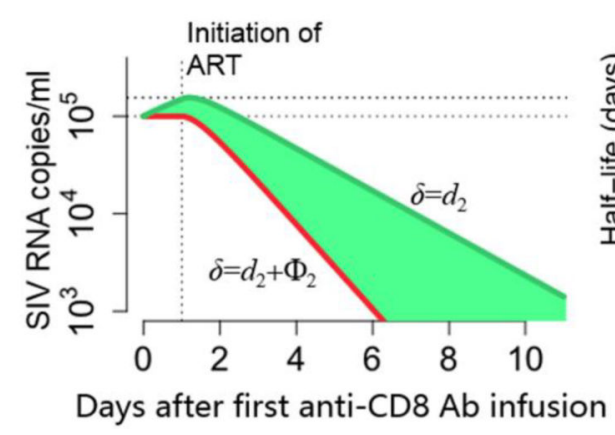

c.

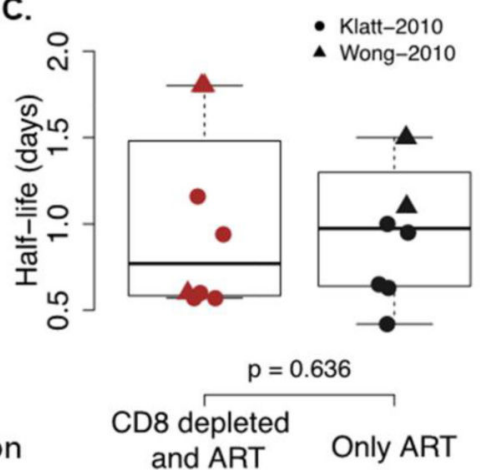

Figure 4. Impact on viral load and infected cell half-life of CD8+ cell depletion followed by antiretroviral treatment.

(A) Schematic representation of the experiments in $(32,33)$. (B) Expected difference in viral load decay slopes, which would correspond to different half-lives of infected cells, $\delta$. (C) Summary of the results obtained with this experiment in $(32,33)$, showing no difference in the half-life of infected cells in the presence and absence of CD8+ cells. Macaque photo from https://www.flickr.com/photos/wild_speedy/4185543087/, under a Creative Commons CC BY-SA 2.0 license (https://creativecommons.org/licenses/by-sa/2.0/). 


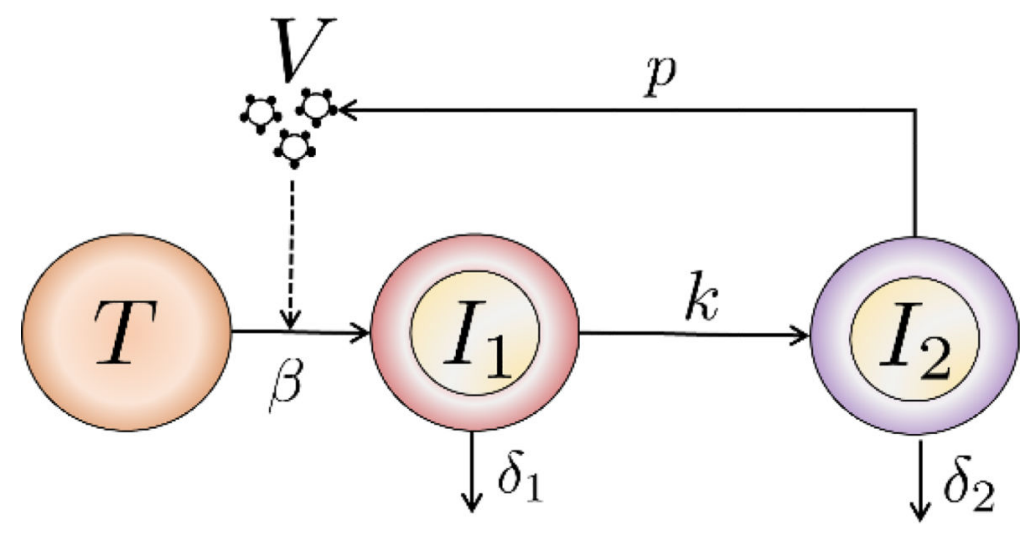

Figure 5. Schematic of a viral dynamics model with multiple stages of infected cells.

Target cells, $T$, become infected but do not produce virus during the early parts of the viral lifecycle $\left(I_{1}\right)$, and infected cells only become productive $\left(I_{2}\right)$ after some time $(\sim 1 / k)$. 


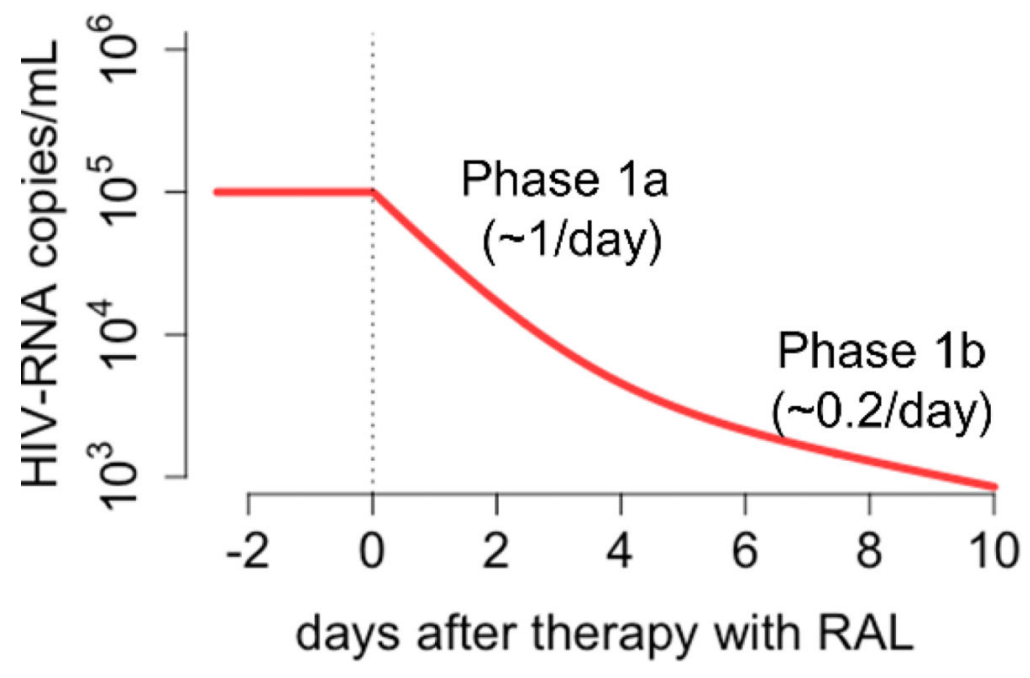

Figure 6. Decay of viral load under integrase strand transfer inhibitors (InSTI).

Phase $1 \mathrm{a}$ and phase $1 \mathrm{~b}$ are shown, including their typical slopes. Note the short timescale on the $\mathrm{X}$-axis, only 10 days. In therapies that do not include an InSTI phase $1 \mathrm{~b}$ is not present, and only phase $1 \mathrm{a}$ is observed. 

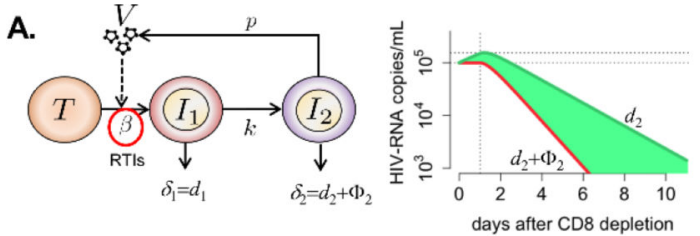

B.

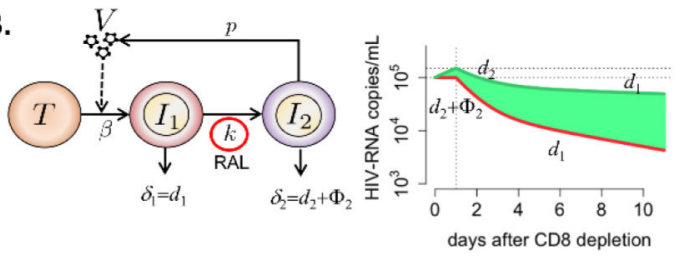

c.
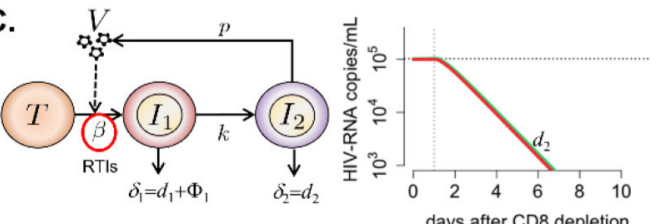

D.

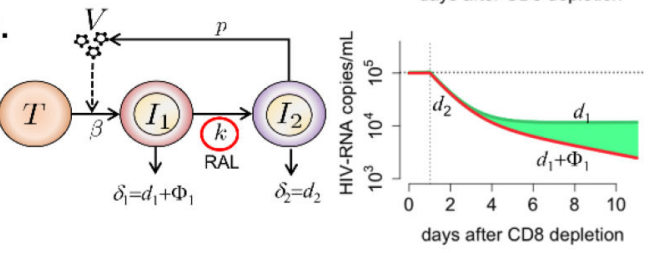

Figure 7. Schematic representation of viral load decline under different scenarios for CD8+ cell effects.

CD8+ cells kill $\left(\Phi_{2}\right)$ productively infected cells, $I_{2}$, and treatment is with (A) RTIs or (B) with RAL. Alternatively, CD8+ cells kill ( $\left.\Phi_{1}\right)$ early stage infected cells, $I_{1}$, and treatment is with (C) RTIs or (D) RAL. The difference in the observed decay in viral load in the presence (red) or absence (blue) of CD8+ cells is shown by the green shaded region. For illustrative purposes, the parameters used were, for RTI treatment $\beta=0$ and RAL efficacy $\omega=0$; for RAL treatment $\omega=0.95$ and $\beta T_{0}=c \delta_{2}\left(\delta_{1}+k\right) / k$. The other parameters were common to both scenarios and fixed at $c=23$ day $^{-1}, k=2.6$ day $^{-1}, \delta_{1}=0.2$ day $^{-1}$ and $\delta_{2}=0.9$ day $^{-1}(89,90)$. In each simulation we represent CD8+ cell depletion by setting $\Phi_{1}$ or $\Phi_{2}$ equal to zero. 


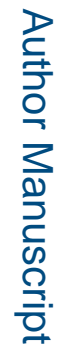

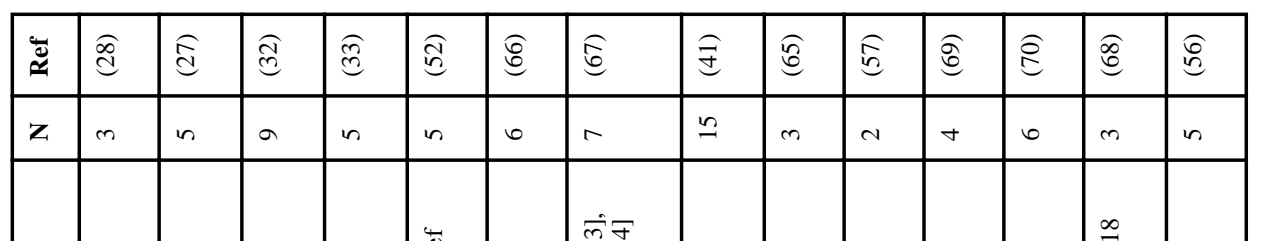

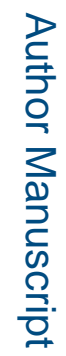

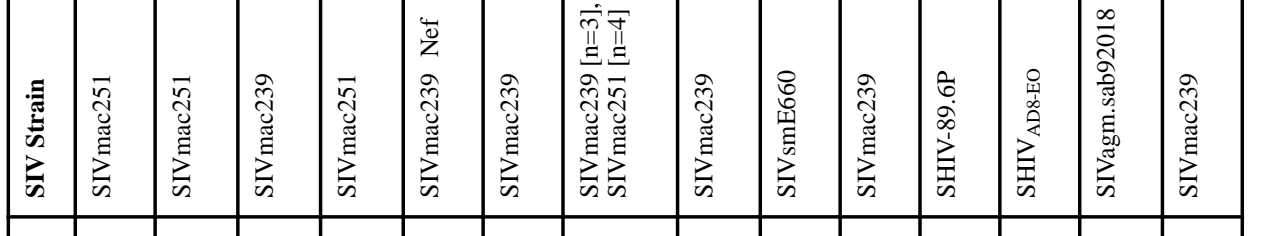

로을

递

录
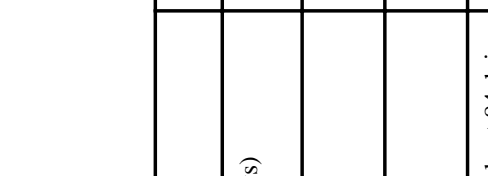